\title{
Proteome analysis of the liver in the Chinese fire-bellied newt Cynops orientalis
}

\author{
X.Y. Zang ${ }^{1,2,3}$, J.L. Guo ${ }^{1,2,3}$, X.F. Geng ${ }^{2,3}$, P.F. Li ${ }^{1,2,3}$, J.Y. Sun ${ }^{1,2,3}$, \\ Q.W. Wang ${ }^{1,2,3}$ and C.S. $\mathrm{Xu}^{1,2,3}$ \\ ${ }^{1}$ College of Life Science, Henan Normal University, Xinxiang, China \\ ${ }^{2}$ State Key Laboratory Cultivation Base for Cell Differentiation Regulation, \\ Henan Normal University, Xinxiang, China \\ ${ }^{3}$ Henan Engineering Laboratory for Bioengineering and Drug Development, \\ Henan Normal University, Xinxiang, China \\ Corresponding author: C.S. Xu \\ E-mail: cellkeylab@126.com
}

Genet. Mol. Res. 15 (3): gmr.15037993

Received November 5, 2015

Accepted January 22, 2016

Published August 12, 2016

DOI http://dx.doi.org/10.4238/gmr.15037993

Copyright (C) 2016 The Authors. This is an open-access article distributed under the terms of the Creative Commons Attribution ShareAlike (CC BY-SA) 4.0 License

\begin{abstract}
The Chinese fire-bellied newt, Cynops orientalis, belonging to Amphibia, Caudata, Salamandridae is a species endemic to China. The liver, which is an important digestive gland and the largest amphibian organ, has various functions, including detoxification, glycogen storage, protein synthesis, and hormone production. However, the newt liver has rarely been studied at the molecular level. We performed histomorphology and high-throughput proteomic analysis of the Chinese fire-bellied newt liver, using hematoxylin and eosin (H\&E) staining and two-dimensional electrophoresis coupled with mass spectrometry. The H\&E staining showed that the newt liver nuclei are large and round, are located in the lateral cytoplasm, and contain a large quantity of lipid droplets. Melanins were abundantly present throughout the hepatic parenchyma. The proteome analysis
\end{abstract}

Genetics and Molecular Research 15 (3): gmr.15037993 
showed a total of 545 proteins detected in the newt liver. Furthermore, a gene ontology analysis suggested that these proteins were associated with metabolism, immune response, cellular homeostasis, etc. Among these, proteins with metabolic functions were found to be the most abundant and highly expressed. This supports the role of the liver as the metabolic center. The proteomic results provide new insights into the aspects of the liver proteomes of the Chinese fire-bellied newt. The identification of a more global liver proteome in the newt may provide a basis for characterizing and comparing the liver proteomes from other amphibian species.

Key words: Newt; Liver; Proteome; Metabolism; Immune response

\section{INTRODUCTION}

Chinese fire-bellied newt Cynops orientalis belonging to order Caudata, family Salamandridae, is mainly distributed in the hilly plains of central and southeastern China (Fei et al., 2006). Compared with Japanese fire-bellied newt (Cynops pyrrhogaster), Chinese fire-bellied newt typically exhibits smoother skin and a rounder tail and has less obvious parotoid glands. Adults typically do best in aquatic habitats with suitable water and some degree of land provided. It has been reported that the newt has advantageous physiological features: sensitiveness to temperature, strong endurance of starvation and sensitive skin to environmental heavy metal (Wang et al., 2012). The newt is now attracting more and more attention of experts, in view of its importance in conservation biology, evolutionary biology, and developmental biology.

The liver as an important digestive gland of amphibians has various functions including detoxification, glycogen storage, protein synthesis, and hormone production. Amphibian livers are usually used as indicator of the quality of the environment. The liver of Chinese fire-bellied newt is located in the right anterior abdominal cavity, whereas the speckled melanin is located on the surface covered by a thin serous membrane. In most amphibian species, it is usually divided into right and left lobes (Grafflin, 1953). However, previous study reported that Chinese fire-bellied newt liver has five lobes (Xie et al., 2011), differing from the conclusion that this species only has right and left lobes (Li et al., 2005). This is because the possibility of region polymorphism in Chinese fire-bellied newt liver maybe exists. Amphibian liver has relatively little connective tissue, and there is no clear boundary among liver lobule.

Currently, most studies about the amphibian liver are mainly focused on histomorphology, but proteomic analysis of the liver in amphibians especially in the newt has not been reported. To understand the functional proteomics of the Chinese fire-bellied newt liver, two-dimensional (2-D) electrophoresis coupled with mass spectrometry (MS) was adopted to separate and identify the proteins in the liver of Chinese fire-bellied newt. The results showed that a total of 545 proteins were detected in the newt liver. Gene Ontology (GO) annotation analysis suggested that these proteins were related to metabolism, immune response, cellular homeostasis, etc. This research may provide a basis for characterizing and comparing the liver proteomes from other amphibian species.

Genetics and Molecular Research 15 (3): gmr.15037993 


\title{
MATERIAL AND METHODS
}

\begin{abstract}
Animals
Three 1-year-old male healthy Chinese fire-bellied newts (Cynops orientalis) were obtained from Jigong Moutain, Xinyang, Henan Province, China. They were anesthetized by $5 \%$ pentobarbital sodium and sacrificed by damaging its central nervous. The body cavity was opened and the liver was removed. Then, the liver was washed in cold PBS, and stored at $-80^{\circ} \mathrm{C}$ for further use. All animal procedures were conducted in strict compliance with the current Animal Protection Law of China. All experiments were performed in strict accordance with institutional guidelines for the care and use of laboratory animals, and protocols were approved by Institutional Animal Care and Use Committee of Henan Normal University in China. Meantime, the newts were not privately owned and the field studies did not involve endangered species.
\end{abstract}

\section{H\&E staining}

The body cavity was opened, and the liver was obtained. Then the liver was OCTembedded, rapidly frozen in liquid nitrogen, and sectioned by freezing microtome $(10 \mu \mathrm{m})$. Sections were stained with haematoxylin for 3-5 min, color separated by hydrochloric acid alcohol for $5 \mathrm{~s}$, back to blue by tap water for $10-15 \mathrm{~min}$, and counterstained with $0.5 \%$ eosin for $15 \mathrm{~s}$. Finally, they were dehydrated by gradient ethanol, cleared in xylene and sealed with neutral gum. Sections were photographed on a Leica microscope (LEICA, Germany).

\section{Protein extraction}

Protein extraction was performed according to the method as previously described (Geng et al., 2014). Briefly, the liver tissues were ground into fine powder with liquid nitrogen, and then suspended in lysis buffer. The suspension was mixed and the supernatant was collected after high speed centrifugation. Susequently, the samples were stored at $-80^{\circ} \mathrm{C}$ for further use. Protein concentration was detected by a 2-D Quantification kit (GE Healthcare, USA).

\section{2-D gel electrophoresis}

Isoelectric focusing (IEF) was performed using Ettan IPGphor according to operating manual and the method previously described (Geng et al., 2015). Briefly, $1000 \mu \mathrm{g}$ protein samples was applied to 24-cm pH 3-10 NL immobilized $\mathrm{pH}$ gradient gel strips in this study. IEF was performed at $250 \mathrm{~V}$ for $1 \mathrm{~h}$, at $1000 \mathrm{~V}$ for $3 \mathrm{~h}$, ramped to $10,000 \mathrm{~V}$ within $3 \mathrm{~h}$, and held at 10,000 V for $14 \mathrm{~h}$. When the IEF was finished, each gel strip was equilibrated in equilibration buffer containing 1\% DTT and subsequently alkylated in alkylation equilibration buffer containing 2.5\% iodoacetamide. The second dimension SDS-PAGE was performed in an electrophoresis device. Finally, the gels were stained with Coomassie brilliant blue, and scanned using a scanner. The abundance value of each protein spot in the scanned images was quantitatively analyzed using ImageMaster 2-D Platinum. The protein spot detected in at least two replicates was further identified by MS.

Genetics and Molecular Research 15 (3): gmr.15037993 


\section{Protein identification by MS}

The selected protein spots were manually excised, decolorized, dehydrated, and whitened according the method previously described (Geng et al., 2015). The dried protein spot was digested with $0.01 \mu \mathrm{g} / \mu \mathrm{L}$ trypsin at $37^{\circ} \mathrm{C}$ overnight. The digested peptides and 0.4 $\mathrm{mg} / \mathrm{mL}$ HCCA solution were orderly placed on MTP AnchorChip ${ }^{\mathrm{TM}}$ 800/384 target. Protein identification was performed by matrix-assisted laser desorption ionization time-of-flight MS (MALDI-TOF/MS), and peptide standard with mass range of 7-32 $\mathrm{kDa}$ was used as external calibration. The instrument parameters were set as follows: reflection mode, peptide mass of $\mathrm{m} / \mathrm{z}$ 700-4200 Da, digestion enzyme of trypsin with one missed cleavage site, fixed modification of carbamidomethyl, variable modification of oxidation, peptide mass tolerance of $\pm 100 \mathrm{ppm}$, fragment mass tolerance of $\pm 0.5 \mathrm{Da}$, number of matched peptide fragments at least 3 pieces.

\section{Database searching}

Mass spectral peaks of $\mathrm{m} / \mathrm{z} \leq 600$ were removed, and the retrieval of peptide fragment was preformed using the BioTools software. The peptide fragments were orderly searched against Swiss-Prot database with taxonomy Salamandridae, Caudata, Amphibia database using MASCOT search engine; if not found, database of Rattus, Mus musculus and Homo sapiens were searched in this study. Only those proteins with the top significant MASCOT scores were considered as acceptable.

\section{RESULTS}

\section{Histology of the Chinese fire-bellied newt liver}

The morphology of the Chinese fire-bellied newt liver was shown in Figure 1. Chinese fire-bellied newt liver has 5 lobes, and is made up of many hepatic lobules and portal area. A central vein passes through the center of the lobe and is surrounded by hepatic cords that radially arrayed between the hepatic cords are irregular hepatic sinusoids. The wall of the hepatic sinusoid is composed by Kupffer and endothelial cells. The Kupffer cell is characterized by well-developed cytoplasmic protrusions. Hepatocyte is polygonal and has spherical or oval euchromatic nuclei. Most hepatocytes contain large numbers of fat droplets within the cytoplasm. A great deal of pigments exists in the liver parenchyma.

\section{Liver proteome of Chinese fire-bellied newt}

Total protein extracts obtained from the Chinese fire-bellied newt liver were separated by 2-D electrophoresis and visualized by Coomassie brilliant blue staining (Figure 2A). The experiment was repeated three times. The protein expression profiles of newt liver were analyzed using the Image Master 7.0 software. After image analysis, a mean of 1078 protein spots were detected. The protein spots detected in at least two replicates were excised from the stained gels. Subsequently, protein identification was performed by MALDI-TOF/MS. The results showed that 545 proteins with the top significant scores were detected in the Chinese fire-bellied newt liver (Table S1).

Genetics and Molecular Research 15 (3): gmr.15037993 


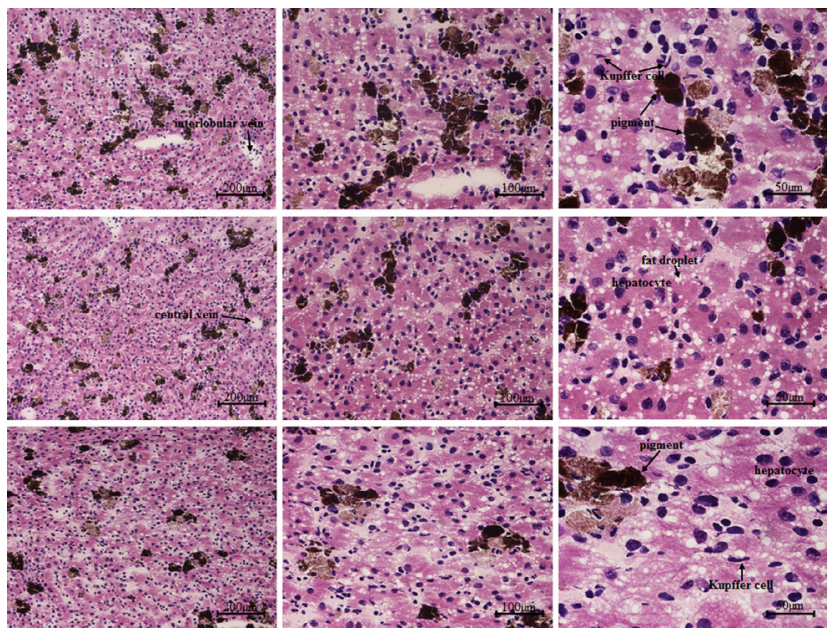

Figure 1. Histologic structure of the Chinese fire-bellied newt liver. The liver was sectioned by freezing microtome $(10 \mu \mathrm{m})$, and the sections were stained with hematoxylin and eosin.
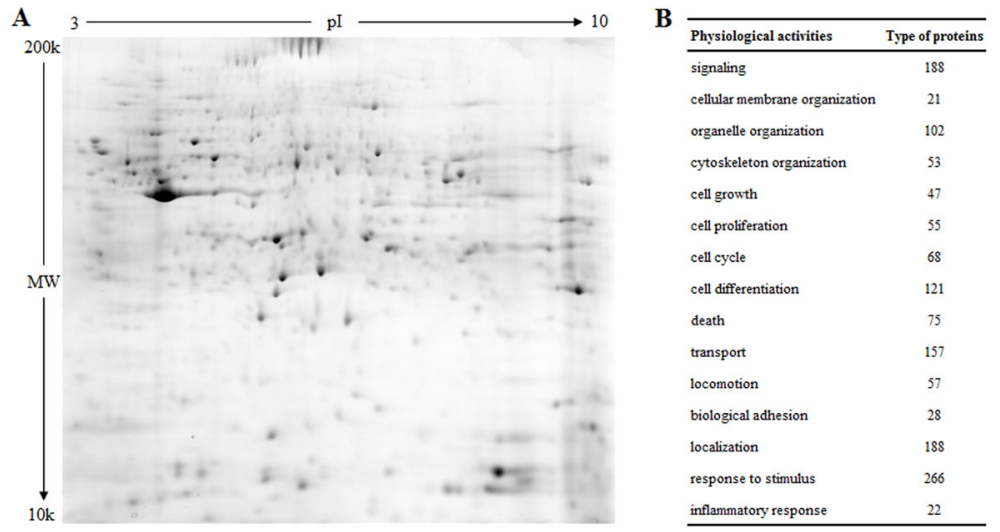

\begin{tabular}{lc}
\hline Physiological actinities & Type of proteins \\
\hline immune response & 42 \\
defense response & 43 \\
carbohydrate metabolic process & 48 \\
lipid metabolic process & 52 \\
protein metabolic process & 168 \\
nuclelic acid metabolic process & 148 \\
organic acid metabolic process & 59 \\
hommone metabolic process & 4 \\
vitamin metabolic process & 8 \\
celluar homeostasis & 31 \\
blood coagulation & 24 \\
blood circulation & 15 \\
organ development & 114 \\
regeneration & 12 \\
other & 110 \\
\hline
\end{tabular}

Figure 2. Kinds and functions of proteins identified in the Chinese fire-bellied newt liver. A. Protein spots detected by two-dimensional electrophoresis. B. Functions of proteins in the Chinese fire-bellied newt liver.

\section{Physiological functions of proteins in the Chinese fire-bellied newt liver}

GO was utilized to annotate biological functions of the identified proteins in the newt liver. A total of 545 proteins were classified into several functional groups (Figure 2B). In view of the characteristics of the liver, we mainly described the proteins associated with metabolism, immune response, cell proliferation and death, cellular homeostasis, blood circulation, blood coagulation, and regeneration.

Liver is an important metabolic organ of body. We identified 296 proteins related to metabolism, including 48 glucose metabolism-related proteins (i.e. glucose-6-phosphate 1-dehydrogenase, fructose-2, 6-biphosphatase 1, hexokinase, phosphoenolpyruvate carboxykinase, and alpha-enolase), 168 protein metabolism-related proteins (i.e. proteasomes, 
histidine ammonia-lyase, ornithine carbamoyltransferase and carbamoyl-phosphate synthase), 52 lipid metabolism-related proteins (i.e., sterol O-acyltransferase 1 and trifunctional enzyme subunit beta), 8 vitamin metabolism-related proteins (i.e., phosphoserine aminotransferase and interferon gamma), 4 hormone metabolism-related proteins (i.e., retinol-binding protein 4 and retinal dehydrogenase 1 ).

The liver is the largest reticuloendothelial system and has stronger immune function. Forty-two proteins were found to be associated with immune response, such as complement component C3 and C5, Toll-like receptor 3, Toll-like receptor 7, lipopolysaccharide-binding protein, and heat-shock $60 \mathrm{kDa}$ protein 1.

The balance between cell proliferation and apoptosis is essential for the development and maintenance of normal organs. In this study, 104 proteins identified in the liver were related to cell proliferation and apoptosis. Among them, 55 proteins participated in cell proliferation including cyclin-dependent kinase 2, cyclin B, piwi-like protein, and katanin p60 ATPasecontaining subunit A1. Seventy-five proteins were involved in apoptosis such as caspase-1, caspase-7, serine/threonine-protein phosphatase and programmed cell death 11 .

Liver plays an important role in maintaining homeostasis and in the regulation of water and electrolyte balance. In this study, 31 proteins were found to be associated with cellular homeostasis. Of them, ferritin and transferrin play a vital role in maintaining hepatocellular homeostasis by regulating ion concentration. Ornithine carbamoyltransferase as a urea cycle enzyme is located almost exclusively in liver mitochondria. Transient receptor potential cation channel subfamily V member 1 (TRPV1) could regulate heat production.

Intrahepatic venous sinus can store a certain amount of blood to compensate shortage of the blood supply. This study showed that 15 proteins were related to blood circulation in the liver, including urotensin-2, nitric oxide synthase, and carbamoyl-phosphate synthase. Almost all coagulation factors are made by the liver, and the liver plays a vital role in maintaining dynamic balance of blood coagulation and anticoagulation. In this study, we identified 24 coagulation-related proteins, including plasminogen activator inhibitor 1 and thrombin.

The liver has strong regeneration capacity, and we identified 12 proteins related to regeneration. These proteins included complement protein $\mathrm{C} 3$ and $\mathrm{C} 5$, lymphoid enhancerbinding factor 1 , heat-shock proteins.

\section{DISCUSSION}

The liver is a vital organ with a variety of functions, including detoxification, protein synthesis, and production of biochemicals. H\&E staining showed that the nuclei of the newt liver are large and round, and located in lateral cytoplasm containing abundant glycogen and lipid droplets, suggesting that hepatocytes represent important storage of energy. In addition, the melanins of the liver pigment cells are situated throughout the hepatic parenchyma. The melanins belong to the reticulohistiocytic system, which may play an important role in eliminating cytotoxic substances (Barni et al., 1999). Xie et al. (2011) reported that the melanin was synthesized in low oxygen conditions and this is due to the result of the protective adaptability of Chinese fire-bellied newt liver. These results are similar to the observation in other newt species.

Furthermore, we found 545 proteins in the Chinese fire-bellied newt liver by 2-D electrophoresis and MALDI-TOF/MS technology. GO annotation analysis showed that these

Genetics and Molecular Research 15 (3): gmr.15037993 
proteins were associated with metabolism, immune response, cell proliferation and death, cellular homeostasis, blood circulation, blood coagulation, regeneration, etc. Delightedly, proteins with metabolic functions have the highest expression abundances in the newt liver, and this is closely related to the role of liver as the metabolic center in any living being.

\section{Glucose metabolism}

The liver is the largest substantial gland and central station of metabolism in vivo. We found a large quantity of metabolism-related proteins in the newt liver. The liver is the main organ capable of metabolizing carbohydrate and storing glycogen. This study identified various glucose metabolism-related proteins in the newt liver. Protein phosphatase 1 regulatory subunit 3B (PPP1R3B), UTP-glucose-1-phosphate uridylyltransferase (UGP2), and phosphoglucomutase-1 (PGM1) detected in the newt liver are associated with glycogenesis and glycogenolysis. Hexokinase and 6-phosphofructo-2-kinase/fructose-2,6-biphosphatase (PFKFB) both expressed in the liver of various animals are the key enzymes in glycolysis (Minchenko et al., 2003; Da Silva et al., 2010). NADP-isocitrate dehydrogenase (NADPIDH) is responsible for 2-oxoglutarate metabolism in the cytoplasm and mitochondria of rat liver (Rakhmanova and Popova, 2006). Glucose-6-phosphate 1-dehydrogenase (G6PD) is the rate-limiting enzyme of the pentose phosphate pathway that supplies reducing energy to cells by maintaining the NADPH level. Phosphoenolpyruvate carboxykinase (PEPCK) as a ratelimiting enzyme of gluconeogenesis has been thought to be essential for glucose homeostasis in hepatocytes (Li et al., 2013). These results suggest that the newt liver has already acquired the essential function of glucose metabolism, and the key enzymes of glucose metabolism in the liver are conservative and indispensable between different animals.

\section{Protein metabolism}

The liver is the only organ to synthesize albumin, and also participates in the generation and regulation of globulin, enzymes and plasma protein. Delightedly, albumin, immunoglobulinbinding protein, plasma cell-induced resident endoplasmic reticulum protein were found in the newt liver. In addition, deamination, transamination and urea synthesis are performed in the liver. Proteins associated with deamination and transamination were found in the newt liver, such as histidine ammonia-lyase (HAL) and alanine-glyoxylate aminotransferase 2 (AGXT2). HAL catalyzes the first reaction in histidine metabolism, the nonoxidative deamination of L-histidine to trans-urocanic acid. AGXT2 is a multifunctional mitochondrial aminotransferase, and takes part in L-alanine metabolism by transamination (Rodionov et al., 2014). Glutamate dehydrogenase required for urea synthesis, mainly exists in the liver, heart and kidney, and converts glutamate to $\alpha$-ketoglutarate (Hamelin et al., 2007). Urea cycle-related proteins mitochondrial ornithine transporter 2, ornithine carbamoyltransferase and carbamoyl-phosphate synthase were identified in the newt liver. Carbamoyl-phosphate synthase catalyzes the synthesis of carbamyl phosphate and acts as a crucial enzyme in urea cycle rate-limiting steps (Weng et al., 2004).

\section{Lipid metabolism}

Lipid metabolism is mainly conducted in the liver, such as the synthesis and

Genetics and Molecular Research 15 (3): gmr.15037993 
decomposition of fat, the formation and oxidation of ketone body, the synthesis of cholesterol, phospholipids and lipoprotein. Several fatty acid beta oxidation-related proteins were found in the newt liver, such as delta(3,5)-delta(2,4)-dienoyl-CoA isomerase $(\mathrm{ECH} 1)$, peroxisome assembly factor 2 (PEX6) and trifunctional enzyme subunit beta (HADHB). ECH1 and HADHB were detected in liver mitochondria of many animals (Lomba et al., 2010; Lanaspa et al., 2015). Fatty acid synthase and arachidonate 5-lipoxygenase found in the newt liver are involved in the synthesis of fatty acids (López-Parra et al., 2008). Apolipoprotein B100 (APOB100) is unique in liver, and plays a role in moving cholesterol around the body. Sterol O-acyltransferase 1 (SOAT1) could regulate hepatic cholesterol 7-hydroxylase, the ratecontrolling enzyme in cholesterol catabolism. In the liver, SOAT1-mediated esterification of cholesterol is involved in the production and release of lipoproteins.

\section{Vitamin and hormone metabolism}

The synthesis and storage of many vitamins, such as vitamins $\mathrm{A}, \mathrm{B}, \mathrm{C}, \mathrm{D}$, and $\mathrm{K}$, are closely associated with the liver. Meantime, the liver can also take part in inactivation of hormone. Phosphoserine aminotransferase is a vitamin B6-dependent enzyme that catalyzes the reversible conversion of 3-phosphohydroxypyruvate to 1-phosphoserine in the phosphorylated pathway of serine biosynthesis and participates in the synthesis of vitamin B6 (Yu et al., 2015). Interferon gamma (IFN- $\gamma$ ) has been reported to be involved in the synthesis of vitamin D (Bikle, 2009). Retinal dehydrogenase 1 (ALDH1), a key enzyme necessary for the production of retinoic acid, participates in retinol metabolism. Retinol-binding protein 4 (RBP4) belongs to the lipocalin family and is the specific carrier for retinol. It delivers retinol from the liver stores to the peripheral tissues.

\section{Immune response}

The liver is the largest reticulohistiocytic system in vivo. A large number of Kupffer cells exist in the hepatic venous sinus endodermis and has powerfully phagocytic capacity (Xie et al., 2011). The melanins found in the newt liver belong to the reticulohistiocytic system and derive from Kupffer cells based on the phagocytic capacity (Barni et al., 1999). The melanins play a vital role in scavenging cytotoxic substance (Frangioni et al., 2005). In this study, we found several proteins that participate in macrophage activation, such as Toll-like receptor 3 (TLR3), TLR7 and lipopolysaccharide-binding protein (LBP). TLR3 and TLR7 are pathogen-recognition receptors for viral RNAs, and regulate innate immune responses by inducing type I interferons (Diebold et al., 2004). LBP is crucial for bacterial signal recognition in phagocytic cells, and plays an important role in modulating LPS-induced inflammatory response (Fang et al., 2013). Moreover, heat-shock $60 \mathrm{kDa}$ protein 1 (HSPD1), tumor necrosis factor ligand superfamily member 4 (TNFSF4), IFN- $\gamma$ and lymphoid enhancer-binding factor 1 (LEF1) are involved in $\mathrm{B}$ cell and $\mathrm{T}$ cell activation. IFN- $\gamma$ is critical for innate and adaptive immunity against viral and bacterial infections, and an important activator of macrophages. LEF1 is a nuclear high mobility group protein that mediates gene transcription in response to canonical $\mathrm{Wnt} / \beta$-catenin signaling pathway. In addition, complement $\mathrm{C} 3$ as a potent inflammatory mediator of the innate immune response, is mainly synthesized in the liver and macrophage, and contributes essentially to the early priming stage of hepatocyte regeneration (Guéguinou et al., 2014). The results indicate that the primary immune response has developed in the newt liver similar to other species.

Genetics and Molecular Research 15 (3): gmr.15037993 


\section{Cellular homeostasis}

The liver is involved in the regulation of water and electrolyte balance. Several proteins indentified in the newt liver are involved in modulating cellular calcium ion homeostasis, metal ion homeostasis, cholesterol homeostasis glucose homeostasis and heat production, such as thioredoxin, ferritin, transferrin, and TRPV1. It has been reported that ferritin could adjust the density of intracytoplasmic iron ion through storing soluble iron ion in liver cells (Anderson and Shah, 2013). Meantime, transferrin transmits iron ion to proliferating cells from hepatic parenchymal cells (Gkouvatsos et al., 2012). At rest states, the heat of the body is mainly produced by the liver. The ability of vertebrates to detect and avoid damaging extremes of temperature depends on the activation of ion channels belonging to the thermo-TRIP family (Zhang et al., 2008). Study has reported that TRPV1 could regulate body temperature and provide sensation of heat (Zhang et al., 2008; Jeong and Seong, 2014). All these facts have highlighted the importance of homeostasis in the newt liver.

\section{Blood circulation and coagulation}

Intrahepatic venous sinus can store a certain amount of blood to compensate shortage of the blood supply. This study found that 15 proteins were related to blood circulation in the liver, including urotensin-2, nitric oxide synthase (NOS) and carbamoyl-phosphate synthase. Urotensin-2 is a potent vasoactive mediator that binds to specific G-protein coupled receptors eliciting either a vasoconstrictive or vasodilatory response (Kemp et al., 2007). Endothelial NOS is thought to control the vasoconstrictive or vasodilatory response by regulating the level of nitric oxide (NO) (Theodorakis et al., 2003). It has been reported that the decreased expression of hepatic NOS results in hepatic sinusoid constriction and the increased hepatic resistance to portal venous flow (Theodorakis et al., 2015).

Almost all coagulation factors are made and regulated by the liver, and the liver plays a vital role in maintaining dynamic balance of blood coagulation and anticoagulation. In this study, several coagulation-related proteins were identified in the newt liver, such as plasminogen activator inhibitor 1 (PAI-1) and thrombin. PAI-1 mainly synthesized in the liver and released in blood, plays a major role in fibrinolysis by inhibiting plasminogen activators (Dimova and Kietzmann, 2008).

\section{CONCLUSIONS}

As amphibians with low extent of evolution, the newt liver is independent, and hepatocytes are arranged in crumb and two layers of cords. Compared with other species with high extent of evolution, the newt liver has already acquired all essential functions. The conclusion of "the more conserved a species is, the more important it is" is again amply demonstrated. According to analysis of expression abundances of proteins, the newt liver is better developed in the aspects of metabolism and immunity, and this echoes the current focus and hotspots in the field of liver study. This research may provide a basis for characterizing and comparing the newt liver proteomes from other amphibian species. Due to the fact that the proteome database of Cynops orientalis is yet to be completed, and the lower repetition rate of 2-D electrophoresis, data obtained from this study require further validation and rectification in the future.

Genetics and Molecular Research 15 (3): gmr.15037993 


\section{ACKNOWLEDGMENTS}

Research supported by grants from the Natural Science Foundation of China (\#31572270), the Major Scientific and Technological Projects of Henan (\#111100910600), and the Doctoral Scientific Research Start-up Foundation of Henan Normal University (\#QD14176).

\section{REFERENCES}

Anderson ER and Shah YM (2013). Iron homeostasis in the liver. Compr. Physiol. 3: 315-330.

Barni S, Bertone V, Croce AC, Bottiroli G, et al. (1999). Increase in liver pigmentation during natural hibernation in some amphibians. J. Anat. 195: 19-25. http://dx.doi.org/10.1046/j.1469-7580.1999.19510019.x

Bikle DD (2009). Vitamin D and immune function: understanding common pathways. Curr. Osteoporos. Rep. 7: 58-63. http://dx.doi.org/10.1007/s11914-009-0011-6

Da Silva D, Zancan P, Coelho WS, Gomez LS, et al. (2010). Metformin reverses hexokinase and 6-phosphofructo-1kinase inhibition in skeletal muscle, liver and adipose tissues from streptozotocin-induced diabetic mouse. Arch. Biochem. Biophys. 496: 53-60. http://dx.doi.org/10.1016/j.abb.2010.01.013

Diebold SS, Kaisho T, Hemmi H, Akira S, et al. (2004). Innate antiviral responses by means of TLR7-mediated recognition of single-stranded RNA. Science 303: 1529-1531. http://dx.doi.org/10.1126/science.1093616

Dimova EY and Kietzmann T (2008). Metabolic, hormonal and environmental regulation of plasminogen activator inhibitor-1 (PAI-1) expression: lessons from the liver. Thromb. Haemost. 100: 992-1006.

Fang H, Liu A, Dirsch O and Dahmen U (2013). Liver transplantation and inflammation: is lipopolysaccharide binding protein the link? Cytokine 64: 71-78. http://dx.doi.org/10.1016/j.cyto.2013.07.025

Fei L, Hu SQ, Ye CY, Huang YZ (2006). Fauna Sinica Amphibia. Beijing Sci. Press: 6.

Frangioni G, Santoni M, Bianchi S, Franchi M, et al. (2005). Function of the hepatic melanogenesis in the newt, Triturus carnifex. J. Exp. Zoolog. A Comp. Exp. Biol. 303: 123-131. http://dx.doi.org/10.1002/jez.a.137

Geng X, Xu T, Niu Z, Zhou X, et al. (2014). Differential proteome analysis of the cell differentiation regulated by BCC, CRH, CXCR4, GnRH, GPCR, IL1 signaling pathways in Chinese fire-bellied newt limb regeneration. Differentiation 88: 85-96. http://dx.doi.org/10.1016/j.diff.2014.10.002

Geng X, Wei H, Shang H, Zhou M, et al. (2015). Proteomic analysis of the skin of Chinese giant salamander (Andrias davidianus). J. Proteomics 119: 196-208. http://dx.doi.org/10.1016/j.jprot.2015.02.008

Gkouvatsos K, Papanikolaou G and Pantopoulos K (2012). Regulation of iron transport and the role of transferrin. Biochim. Biophys. Acta 1820: 188-202. http://dx.doi.org/10.1016/j.bbagen.2011.10.013

Grafflin AL (1953). In vivo studies of hepatic structure and function in the salamander. Anat. Rec. 115: 53-61. http://dx.doi. org/10.1002/ar.1091150105

Guéguinou N, Huin-Schohn C, Ouzren-Zarhloul N, Ghislin S, et al. (2014). Molecular cloning and expression analysis of Pleurodeles waltl complement component $\mathrm{C} 3$ under normal physiological conditions and environmental stresses. Dev. Comp. Immunol. 46: 180-185. http://dx.doi.org/10.1016/j.dci.2014.04.011

Hamelin M, Mary J, Vostry M, Friguet B, et al. (2007). Glycation damage targets glutamate dehydrogenase in the rat liver mitochondrial matrix during aging. FEBS J. 274: 5949-5961. http://dx.doi.org/10.1111/j.1742-4658.2007.06118.x

Jeong KY and Seong J (2014). Neonatal capsaicin treatment in rats affects TRPV1-related noxious heat sensation and circadian body temperature rhythm. J. Neurol. Sci. 341: 58-63. http://dx.doi.org/10.1016/j.jns.2014.03.054

Kemp W, Krum H, Colman J, Bailey M, et al. (2007). Urotensin II: a novel vasoactive mediator linked to chronic liver disease and portal hypertension. Liver Int. 27: 1232-1239.

Lanaspa MA, Epperson LE, Li N, Cicerchi C, et al. (2015). Opposing activity changes in AMP deaminase and AMPactivated protein kinase in the hibernating ground squirrel. PLoS One 10: e0123509. http://dx.doi.org/10.1371/ journal.pone.0123509

Li C, Shu ZJ, Lee S, Gupta MB, et al. (2013). Effects of maternal nutrient restriction, intrauterine growth restriction, and glucocorticoid exposure on phosphoenolpyruvate carboxykinase-1 expression in fetal baboon hepatocytes in vitro. $J$. Med. Primatol. 42: 211-219. http://dx.doi.org/10.1111/jmp.12048

Li SC, Liu XL and He X (2005). Morphologic observation and anatomical study on Cynops orientalis. Chin. J. Vet. Sci. Technol. 35: 60-63.

Lomba A, Milagro FI, García-Díaz DF, Marti A, et al. (2010). Obesity induced by a pair-fed high fat sucrose diet:

Genetics and Molecular Research 15 (3): gmr.15037993 
methylation and expression pattern of genes related to energy homeostasis. Lipids Health Dis. 9: 60. http://dx.doi. org/10.1186/1476-511X-9-60

López-Parra M, Titos E, Horrillo R, Ferré N, et al. (2008). Regulatory effects of arachidonate 5-lipoxygenase on hepatic microsomal TG transfer protein activity and VLDL-triglyceride and apoB secretion in obese mice. J. Lipid Res. 49: 2513-2523. http://dx.doi.org/10.1194/jlr.M800101-JLR200

Minchenko O, Opentanova I and Caro J (2003). Hypoxic regulation of the 6-phosphofructo-2-kinase/fructose-2,6bisphosphatase gene family (PFKFB-1-4) expression in vivo. FEBS Lett. 554: 264-270. http://dx.doi.org/10.1016/ $\underline{\text { S0014-5793(03)01179-7 }}$

Rakhmanova TI and Popova TN (2006). Regulation of 2-oxoglutarate metabolism in rat liver by NADP-isocitrate dehydrogenase and aspartate aminotransferase. Biochemistry (Mosc.) 71: 211-217. http://dx.doi.org/10.1134/ $\underline{\text { S0006297906020143 }}$

Rodionov RN, Jarzebska N, Weiss N and Lentz SR (2014). AGXT2: a promiscuous aminotransferase. Trends Pharmacol. Sci. 35: 575-582. http://dx.doi.org/10.1016/j.tips.2014.09.005

Theodorakis NG, Wang YN, Skill NJ, Metz MA, et al. (2003). The role of nitric oxide synthase isoforms in extrahepatic portal hypertension: studies in gene-knockout mice. Gastroenterology 124: 1500-1508. http://dx.doi.org/10.1016/ $\underline{\text { S0016-5085(03)00280-4 }}$

Theodorakis NG, Wang YN, Korshunov VA, Maluccio MA, et al. (2015). Thalidomide ameliorates portal hypertension via nitric oxide synthase independent reduced systolic blood pressure. World J. Gastroenterol. 21: 4126-4135. http:// dx.doi.org/10.3748/wjg.v21.i14.4126

Wang DH, Hu JR, Wang LY, Hu YJ, et al. (2012). The apoptotic function analysis of p53, Apaf1, Caspase3 and Caspase7 during the spermatogenesis of the Chinese fire-bellied newt Cynops orientalis. PLoS One 7: e39920. http://dx.doi. org/10.1371/journal.pone.0039920

Weng L, Wong WP, Chew SF and Ip YK (2004). Excretory nitrogen metabolism in the Chinese fire-belly newt Cynops orientalis in water, on land, or in high concentrations of environmental ammonia. J. Comp. Physiol. B 174: 113-120. http://dx.doi.org/10.1007/s00360-003-0395-Z

Xie ZH, Zhong HB, Li JH and Hou YJ (2011). The Structural Organization of the Liver in the Chinese Fire-bellied Newt (Cynops orientalis). Int. J. Morphol. 29: 1317-1320. http://dx.doi.org/10.4067/S0717-95022011000400041

Yu J, Xiao F, Guo Y, Deng J, et al. (2015). Hepatic Phosphoserine Aminotransferase 1 Regulates Insulin Sensitivity in Mice via Tribbles Homolog 3. Diabetes 64: 1591-1602. http://dx.doi.org/10.2337/db14-1368

Zhang X, Li L and McNaughton PA (2008). Proinflammatory mediators modulate the heat-activated ion channel TRPV1 via the scaffolding protein AKAP79/150. Neuron 59: 450-461. http://dx.doi.org/10.1016/j.neuron.2008.05.015

\section{Supplementary material}

Table S1. Proteins identified in the Chinese fire-bellied newt liver. 